\title{
Potential Applications of Robotics in Medical Management- A Review
}

\author{
Geetha Anandhi $\mathbf{C}^{1}$, Nithyaa A.N ${ }^{2}$ \\ M.E in Medical Electronics, BME Dept., Rajalakshmi Engineering College, Chennai, India ${ }^{1}$ \\ Assistant Professor (SG), BME Dept., Rajalakshmi Engineering College, Chennai, India ${ }^{2}$
}

\begin{abstract}
The most neglected topic in health protection facilities is the management of the wastes generated by them. Health hazard wastes are the wastes that are produced from health protection facilities, laboratories, and research centers, animal test laboratories, mortuary and autopsy centers, blood banks, nursing homes for the elderly, etc. As per the World Health Organization (WHO), it is been stated that nearly $85 \%$ of wastes generated in health protection sectors are non-hazardous and the rest $15 \%$ is hazardous. Until now we are following manual sorting and handling of Bio-Medical Wastes (BMW). The purpose of the review is to: (i) evaluate the generation of biomedical wastes; (ii) analyze methodologies used in biomedical waste management (iii) explain advantages of replacing humans with robotic arms in health care waste management system (iv) Identify the applications of artificial intelligence in healthcare sectors (v) explain the application of image processing methodologies in waste segregation and disposal. The results from various authors give us a detailed explanation of how image processing techniques, neural networks, and robotics can be applied in healthcare waste management system. These above-mentioned technologies enable us to gain knowledge about how to prevent disease transmission in healthcare workers as a result of BMW.
\end{abstract}

Keywords: BMW, robotics, image processing, object recognition, manpower, autonomous waste disposal.

\section{INTRODUCTION}

All types of wastes generated as a result of medical activities are said to be HealthCare Wastes (HCW). The problems that occur as a result of biomedical wastes are the most ignored issue. Biomedical waste management is the lowly prioritized topic always. Whenever someone gets exposed to healthcare wastes it might lead to diseases or injury.

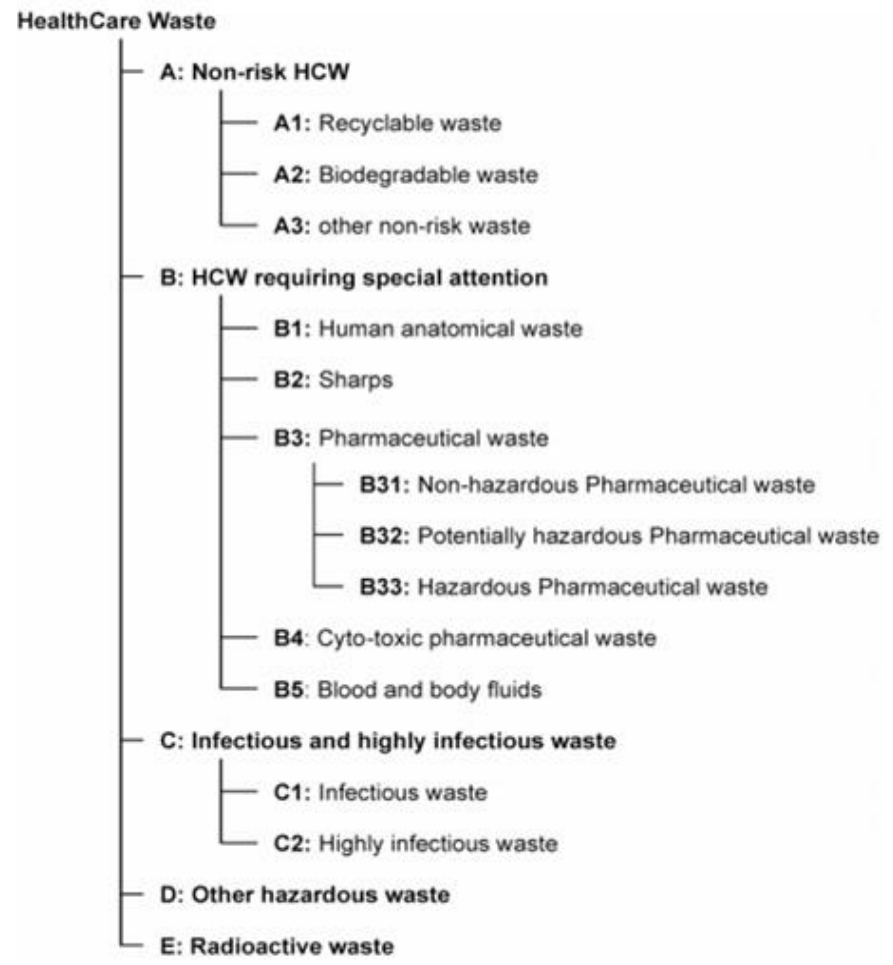

Figure 1 HCW classification based on WHO [1] 


\section{International Journal of Advanced Research in Computer and Communication Engineering}

Vol. 9, Issue 11, November 2020

DOI 10.17148/IJARCCE.2020.91115

They are causing serious health effects because they possess agents that lead to some serious infection, they may cause mutations in their genetic information, may contain harmful chemicals and drugs, the substance might emit radiations, they may lead to sharp inflicted injury as a result of sharps. Fig (1) describes the health care waste classification as per WHO norms. The wastes are classified because each of them should be disposed of separately. Each type of waste is made of diverse materials. As per WHO about $15 \%$ of health care wastes are hazardous and may contain sharps. If such wastes are handled by humans themselves, it will lead to severe infection transmission to healthy waste handlers from the infected or contaminated waste substances. In such scenarios to prevent the transmission of diseases such as AIDS, Hepatitis B, Hepatitis C, in health care workers, we should replace humans with robots.[1]

\section{A. TYPES OF WASTES:}

Wastes that are produced from the healthcare facilities are not made of the same type of materials. The basic classification as per World Health Organization (WHO) is as follows;

- $\quad$ Infectious waste

- $\quad$ Pathological waste

- $\quad$ Sharps waste

- $\quad$ Chemical waste

- $\quad$ Pharmaceutical waste

- $\quad$ Cytotoxic waste

- $\quad$ Radioactive waste

- $\quad$ Non-hazardous or general waste

Infectious waste is the waste from the discarded diagnostic samples that might be contaminated with blood and other bodily fluids, waste from autopsies and infected animals from laboratories containing infectious agents or swabs, bandages, and disposable medical devices which may be from infected patients. Pathological waste includes body parts, tissues, organs, and body fluids, parts of the human body, and animal carcasses that are contaminated. Sharps waste is any waste material that punctures the human's skin falls under this category. Needles, scalpels that are for one-time use, syringes, blades, etc. Chemical waste is used in reagents and solvents in laboratories, sterilants, and some medical devices that contain heavy metals such as mercury, disinfectants. Pharmaceutical waste is the wastes that are contaminated, expired, unused medicines, drugs, and vaccines. Cytotoxic waste comprises thewaste that contains substances that leads to a genetic mutation. E.g. Cytotoxic drugs that are used in cancer therapy. Radioactive waste is radioactive diagnostic material or radiotherapeutic materials. Non-hazardous or general waste is the general waste that causes no risk of infection and any other health hazard. In this review paper, we will be discussing health care waste management based on robotics principles. Specifically, the review paper deals with the color recognition based object pick and drop concept in waste disposal strategy.[1]

\section{RISKS ASSOCIATED WITH BIOMEDICAL WASTE (BMW)}

The process of the BMW management system starts with waste classification, waste segregation, waste minimization, handling and collection, on-site transport and storage, treatment, and disposal. Firstly it is important to segregate BMW to reduce the risks associated with exposure of hazardous wastes for waste handlers[2]. Most hospitals are mixing hospital waste with general wastes. It leads to infection risk or injury for the person who collects such waste materials. It is been stated that only $38.7 \%$ of hospitals only follow correct procedures in health care waste segregation as per the Ministry of health and population, Nepal, 2012. Risk perception is very low among health care workers who handle BMW. It is about only $43 \%$ of them are aware of Acquired Immune Deficiency Syndrome (AIDS) may be acquired accidentally, $40 \%$ of them accepted Hepatitis B (HBV) or Hepatitis C (HCV) may be transmitted, $50.8 \%$ of them have poor risk perception and $49.2 \%$ of them have good perception. Their perception about handling waste is very poor as they are saying all health care wastes cause harm and no radioactive waste harm.[3] Every year human scavengers are facing lots of trouble as a result of biomedical waste. It includes needle stick injuries, headache, dizziness, vomiting, itching, burning sensation in eyes, skin rashes, cough, breathing difficulty while incinerating the wastes. Every year it is reported that 2 million health care workers are exposed to needle injuries. Such a scenario leads to a high risk of AIDS, $\mathrm{HBV}$, and $\mathrm{HCV}$ transmission. As a result of handling infected health care waste, the life of health care workers and waste handlers are at risk. As far as 2010 is concerned unsafe usage of injections resulted in 33,800 new AIDS cases, 1.7 million cases of HBV infection, 3, 15,000 cases of HCV infection.

\section{III.COLOUR CODING IN BIOMEDICAL WASTE MANAGEMENT}

The system of biomedicl waste segregation should be the same throughout the country. The waste segregation categories to be used and a system of color coding for waste containers have been prescribed in many nations' legislation. World Health Organization (WHO) scheme of color coding in waste segregation is available (Table 1). 


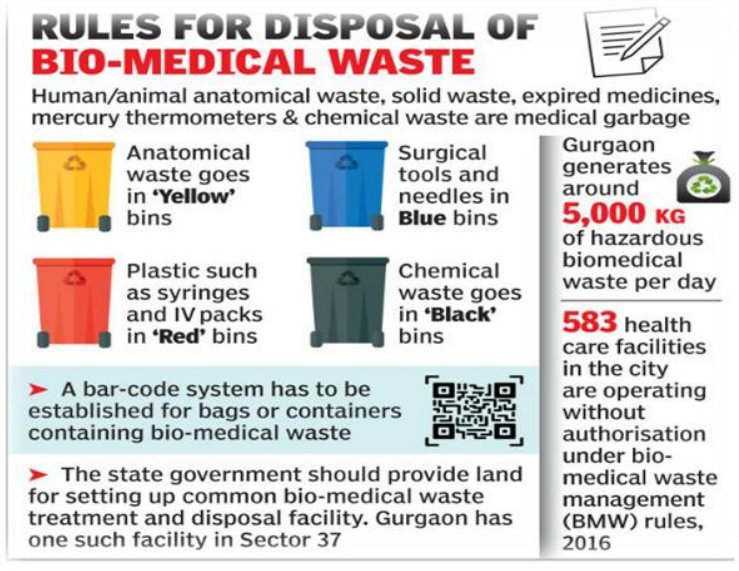

Figure 2 Color bins for waste segregation

Courtesy: https://timesofindlia.indiatimes.com/city/gurgaon/600-clinics-and-labs-violate-biowaste-rulles-faceclosure/articleshow/74017081.cms

It is very easy for any medical personnel or medical worker to throw the waste substances into the correct bin due to difference of color. It is also a visual indication as color coding alerts us about its hazardous nature, thereby reducing accidental injuries. The color coding of the bins as per the type of waste and few rules in Haryana in regard to BMW fig(2). All the waste containers must be labeled so that their source could be identified, their type and quantity could be recorded. Simply attaching labels with an international hazard symbol to each waste container is highlyrecommended.[4]

Table 1 WHO scheme of waste segregation[4]

\begin{tabular}{|l|l|l|}
\hline \multicolumn{1}{|c|}{ Type of waste } & \multicolumn{1}{|c|}{ Color of container and markings } & \multicolumn{1}{c|}{ Type of container } \\
\hline Highly infectious waste & $\begin{array}{l}\text { Yellow, marked "HIGHLY } \\
\text { INFECTIOUS", with biohazard symbol }\end{array}$ & $\begin{array}{l}\text { Strong, leak-proof plastic } \\
\text { bag, or container capable of } \\
\text { being autoclaved }\end{array}$ \\
\hline $\begin{array}{l}\text { Other infectious waste, pathological } \\
\text { and anatomical waste }\end{array}$ & Yellow with biohazard symbol & $\begin{array}{l}\text { Leak-proof plastic bag or } \\
\text { container }\end{array}$ \\
\hline Sharps & $\begin{array}{l}\text { Yellow, marked “SHARPS”, with } \\
\text { biohazard symbol }\end{array}$ & Puncture-proof container \\
\hline Chemical and pharmaceutical waste & $\begin{array}{l}\text { Brown, labeled with appropriate hazard } \\
\text { symbol }\end{array}$ & Plastic bag or rigid container \\
\hline Radioactive waste & Labeled with radiation symbol & Lead box \\
\hline General health-care waste & Black & Plastic bag \\
\hline
\end{tabular}

\section{IV.ARTIFICIAL INTELLIGENCE (AI)}

AI is the broadest field in the field of Computer Science. AI's practical field is machine learning. Humans are the most intelligent creatures. The human brain comprises millions of neurons performing some specific task. Further, there are certain branches such as Artificial Neural Network (ANN), Convolutional Neural Networks (CNN), Recurrent Neural Network (RNN), Deep learning, computer vision, symbolic learning, etc. If we replicate the neuronal structure in machines, they will be able to perform almost all the activities that a human could do. Image processing became a major required field for the machine to perform computer vision. Human Eyes can be able to see the surroundings and able to process them, this comes under Computer vision (Robotics). The usage of AI in health care has doubled in the year 2016(fig. 3).[5] Among all the AI techniques compute vision plays a major role computer vision is highly used in the health care sector based on object recognition and color recognition. The lowly prioritized topic in the health care sector is healthcare waste management. With the rise in the trend of AI, replacing humans with robots to perform hazardous waste disposal tasks will be an excellent application. For computer vision, Camera model, image sensing 


\section{International Journal of Advanced Research in Computer and Communication Engineering}

Vol. 9, Issue 11, November 2020

DOI 10.17148/IJARCCE.2020.91115

devices, and color models are important for image acquisition. Some of the color models are the RGB model, YUV model, CYMB model, HLV and HSV model, etc.[6].

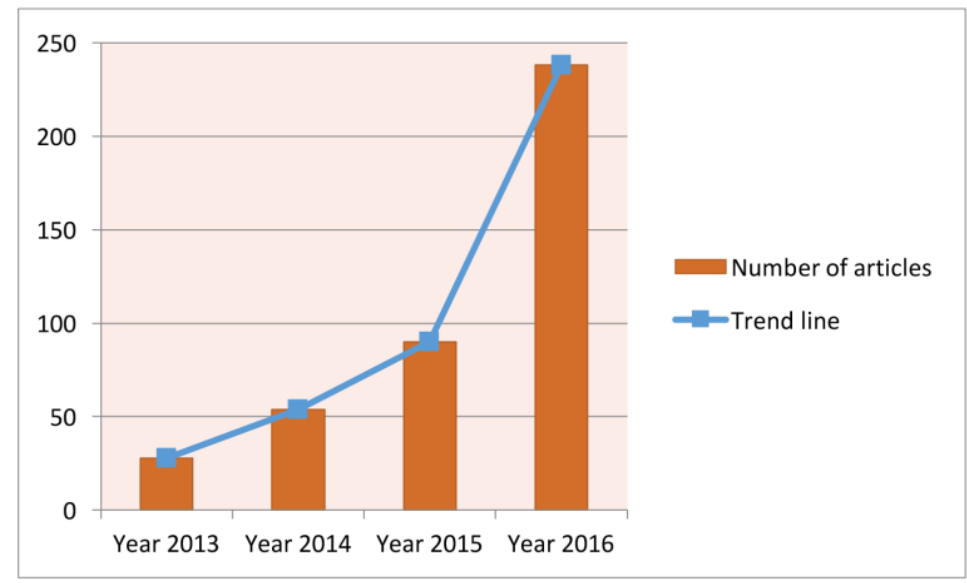

Figure 3 Current trend for deep learning [5]

\section{ROBOTICS IN MEDICINE}

Any kind of machinery that helps humans to complete some specific task is said to be a robot. Most popularly robots are made to do some hazardous task that a human cannot perform. Some of them will work at a higher rate of independence that they don't require any manual operation are said to be autonomous robots. Few bots require manual operation such bots are said to be non-autonomous robots. Manipulation robotic systems are classified as autonomous robots, remote-controlled robots, and manually operated robots. The autonomous robots are further classified as programmable, non-programmable, adaptive, and intelligent robots. Fig (4) represents an adaptive robot. Their role is of huge importance in many areas such as industries. Space communications, military applications, and especially in medical sectors.[7]

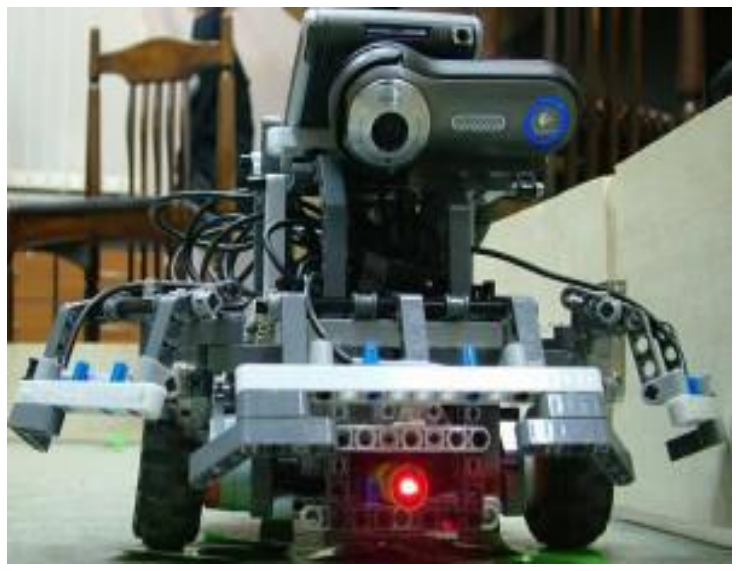

Figure 4 Adaptive Robot [7]

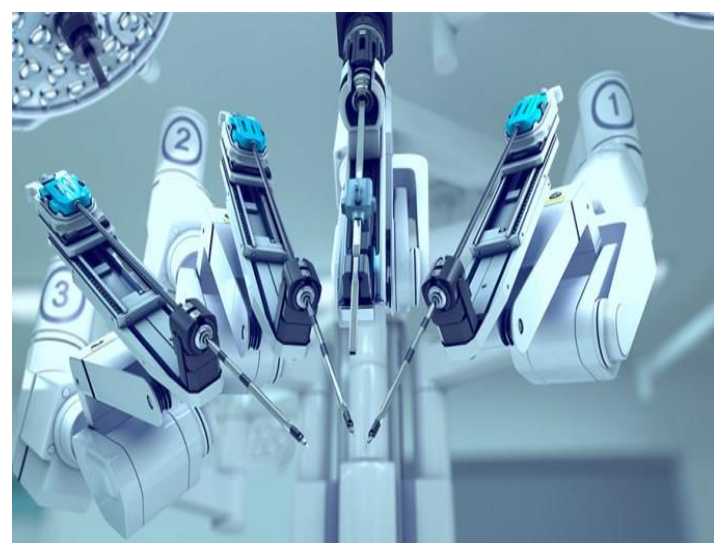

Figure 5 Surgical robot $[8]$

The main applications of robots in the medical field are that they are been used in teleconsultation where doctors could be able to examine the patient remotely. To perform minimally invasive procedures robotic surgeons play a very important role. Fig (5) represents a robot performing surgery assisted by a surgeon in a remote area. Certain robots help people with certain disabilities to improve their quality of life such robots are said to be rehabilitation robots. Also, few robots are involved in medical transportations, acts as surgical assistants, prescription dispensing system, etc. [8]

\section{VI.PICK AND PLACE ROBOTS}

Robots are general-purpose programmable electromagnetic machines possess the features of human being and they run as a result of computer codes. Picking and placing the objects is a major task in industrial sites [9]. Numerous strategies have been proposed for vision-based getting a control handle. While getting a handle on undertakings, the robot needs 


\title{
International Journal of Advanced Research in Computer and Communication Engineering
}

\author{
Vol. 9, Issue 11, November 2020
}

DOI 10.17148/IJARCCE.2020.91115

prior information on-scene investigation [10]. It requires undertaking two steps such as object reconstruction and grasping planning. Fuzzy logic [10], neural network, visual servoing for an image, and position are major techniques for object grasping [9], etc. Vision processing, position calculation, orientation algorithm, coordinate transformation, and guideline unraveling to the robot are required steps to control the robotic arm based on the object's location and its orientation [11]. OpenCV library is used to program the machine. Object recognition, image preprocessing, converting pixel co-ordinate to world co-ordinate, and calculation of an object's orientation so that it will provide us with guidance about the angle of the robot's rotation.[12] Gaussian mixture models and probabilistic graphical models are used in object selection during grasp planning.[13]. visual odometry calculation is conceivable of being actualized in real-time and can be additionally improved in the mix with probabilistic sensor combination calculations furthermore, extra discernment gadgets as in present status of-the-craftsmanship in a visual route are described in[14-20].

\section{COLOUR DETECTION IN RGB SPACE}

Computer vision Performs various operations in which object recognition is an important one. object sorting can be made easier with the help of size and the color of the object. Color detection is used most often technique. Mitsubishi Movemaster RV-M1 is a robot manipulator that was integrated with a webcam for image processing of round objects as described in [21]. The classical structure consists of one neural network is also good at classifying image based on colors in RGB space but as the complexity of image increases multiple perceptron layers will producebetter results is described in[22]. RGB is converted to $\mathrm{HSV}$ and $\mathrm{YCbCr}$ in another application because it was assumed that RGB is more sensitive to illumination [23]. As far as computer vision is concerned cameras will be attached to robots to classify objects based on colors. So RGB color space algorithm is the best even if it is sensitive to illumination it is said to give better segmentation results in real time[24]. So color detection-based object recognition robots play an important role in the health care sectors.

\section{CONCLUSION}

Robotics, computer vision, machine learning, object recognition, color detection, image processing are playing a prior role in the present era. The major problem that is not given much priority is health care waste management system. Most of hospitals are not following the correct way of waste segregation and disposal. Also, the most workers are having poor perception. If robots are used to dispose of waste substance from health care sectors, rate of disease transmission via infected needles or BMW could be reduced abruptly. A new step was taken by Sfax Governorate, Tunisia to dispose health care wastes based on Analytic Hierarchy Process (AHP) implemented in Expert choice software[25].Each type of hospital are to be segregated in different coloured bins (Blue, White, Red and yellow). RGB color space algorithm can be fed to a robotic arm to pick and drop the wastes in to the appropriate bins. This review paper gives a new approach in handling autonomous waste via robots. In future based on the concepts reviewed in this review paper an autonomous robot will be designed based on real time color detection based on RGB color spacealgorithm.

\section{REFERENCES}

[1]WHO, "Fundamentals of health-care waste management," United Nations Environmental Program., no. 1, pp. 7-23, 2002,[Online].Available:http://www.who.int/mediacentre/factsheets/fs231/en/\%0Ahttp://www.who.int/water_sanitation_health/medicalwaste/e n/guidancemanual1.pdf.

[2]G. H. W. W. UNDP, "MODULE 9 : Classification of Healthcare Waste Module Overview."

[3]S. Karki, S. R. Niraula, and S. Karki, "Perceived risk and associated factors of healthcare waste in selected hospitals of Kathmandu, Nepal," PLoS One, vol. 15, no. 7 July, pp. 1-10, 2020, DOI: 10.1371/journal.pone.0235982.

[4]J. Emmanuel et al., "Safe management of wastes from health care activities.," Bull. World Health Organ., vol. 79, no. 2, pp. 171-171, 2001, DOI: 10.1590/S0042-96862001000200013.

[5]F. Jiang et al., "Artificial intelligence in healthcare: Past, present, and future," Stroke Vasc. Neurol., vol. 2, no. 4, pp. 230-243, 2017, DOI: 10.1136/svn-2017-000101.

[6]P. R. G. Kurka and A. A. Díaz Salazar, "Applications of image processing in robotics and instrumentation," Mech. Syst. Signal Process., vol. 124, pp. 142-169, 2019, DOI: 10.1016/j.ymssp.2019.01.015.

[7]https://www.elprocus.com/different-types-of-autonomous-robots-and-real-time-applications/

[8] https://orthofeed.com/2018/01/09/top-6-robotic-applications-in-medicine/

[9] Chi-Yi Tsai, Ching-Chang Wong, Chia-Jun Yu, Chih-Cheng Liu, and Tsung-Yen Liu, "A Hybrid Switched Reactive-Based Visual Servo Control of 5-DOF Robot Manipulators for Pick-and-Place Tasks", IEEE SYSTEMS JOURNAL, VOL. 9, NO. 1, MARCH 2015.

[10] Vincenzo Lippiello, Fabio Ruggiero, Bruno Siciliano, and Luigi Villani "Visual Grasp Planning for Unknown Objects Using a Multifingered Robotic Hand" IEEE/ASME TRANSACTIONS ON MECHATRONICS, VOL. 18, NO. 3, JUNE 2013

[11] P. Andhare and S. Rawat, "Pick and place industrial robot controller with computer vision," 2016 International Conference on Computing Communication Control and Automation (ICCUBEA), Pune, 2016, pp. 1-4, DOI: 10.1109/ICCUBEA.2016.7860048.

[12]ABB:www02.abb.com/global/zaabb/zaabb011.nsf/bf177942f19f4a98c1257148003b7a0a/0f55ae5d8012b4a6c1257b7200358d2e/\$file/dmro+1++introduction+to+robotics.pdf

[13] Dan Song, Carl Henrik Ek, Kai Huebne , and Danica Kragic "Task-Based Robot Grasp Planning Using Probabilistic Inference" IEEE TRANSACTIONS ON ROBOTICS, VOL. 31, NO. 3, JUNE 2015 


\title{
International Journal of Advanced Research in Computer and Communication Engineering
}

\author{
Vol. 9, Issue 11, November 2020
}

\section{DOI 10.17148/IJARCCE.2020.91115}

[14] D. S. B. Tilakaratna, U. Watchareeruetai, S. Siddhichai, and N. Natcharapinchai, "Image analysis algorithms for vehicle color recognition," 2017 International Electrical Engineering Congress (iEECON), Pattaya, 2017, pp. 1-4, DOI: 10.1109/IEECON.2017.8075881

[15]J. V. Delgado, P.R.G. Kurka, The Use of a Graphics Processing Unit (GPU) in a Real-Time Visual Odometry Application, in 2015 IEEE Int. Conf. Dependable Syst. Networks Work., IEEE, 2015: pp. 141-146. doi:10.1109/DSN-W.2015.32.

[16] M. Roth, G. Hendeby, F. Gustafsson, Nonlinear Kalman filters explained: a tutorial on moment computations and sigma point methods, J. Adv. Inf.Fusion. 11 (2016) 47-70.

[17] S.Y. Chen, Kalman filter for robot vision: a survey, IEEE Trans. Ind. Electron. 59 (2012) 4409-4420, https://doi.org/10.1109/TIE.2011.2162714.

[18] F. Gustafsson, Particle filter theory and practice with positioning applications, IEEE Aerosp. Electron. Syst. Mag. 25 (2010) 53-82, https://doi.org/

[19] D. Scaramuzza, F. Fraundorfer, Visual Odometry [Tutorial], IEEE Robot. Autom. Mag. 18 (2011) 80-92, https://doi.org/10.1109/MRA.2011.943233.

[20] F. Fraundorfer, D. Scaramuzza, Visual Odometry: Part II: Matching, Robustness, Optimization, and Applications, IEEE Robot. Autom. Mag. 19 (2012)78-90, https://doi.org/10.1109/MRA.2012.2182810.

[21] A. Djajadi, F. Laoda, R. Rusyadi, T. Prajogo, and M. Sinaga, "A MODEL VISION OF SORTING SYSTEM APPLICATION USING ROBOTIC MANIPULATOR", [Online].Available:http://journal.uad.ac.id/index.php/TELKOMNIKA/article/view/615/424. [Accessed: 21- Sep- 2017].

[22] H. Altun, R. Sinekli, U. Tekbas, F. Karakaya, and M. Peker, "An efficient color detection in RGB space using hierarchical neural network structure," 2011 International Symposium on Innovations in Intelligent Systems and Applications, Istanbul, 2011, pp. 154-158, DOI: 10.1109/INISTA.2011.5946088.

[23] P. Sebastian, Y. V. Voon, and R. Comley, "The Effect of Colour Space on Tracking Robustness", Industrial Electronics and applications, 2008. ICIEA 2008. 3rd IEEE Conference on, pp.2512-2516, 3-5 June 2008

[24] U. L. Jau, C. S. Teh, and G. W. Ng, "A comparison of RGB and HSI color segmentation in real-time video road sign detection", Information Technology, 2008.

[25] D. Baati, M. Mellouli, and W. Hachicha, "Designing a new infectious healthcare-waste management system in Sfax governorate, Tunisia," 2014 International Conference on Advanced Logistics and Transport (ICALT), Hammamet, 2014, pp. 350-355, DOI: 10.1109/ICAdLT.2014.6866337.

\section{BIOGRAPHY}

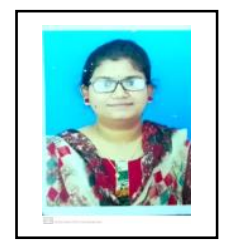

Geetha Anandhi C has completed B.Tech in Biomedical Engineering (First class with distinction - Gold medalist) and is currently pursuing M.E in medical Electronics. She has worked as Trainee Associate Biomedicine in SPi Global,Pondicherry for the period of 8 months.Her research interests are biomedical instrumentation, biomaterials and rehabilitation engineering.

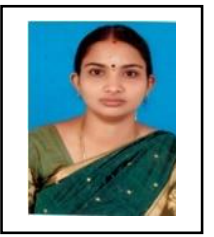

Nithyaa A N. has completed Bachelors in Electrical and Electronics Engineering and done Masters in Biomedical Engineering. She is also doing her Doctorate in Rehabilitation Engineering under Anna University. Currently, she is working as an Assistant Professor (SG) with a working experience of 13 years. She have published many research and review articles under the research interest of Biomedical instrumentation, Medical image processing, Bio-signal processing and rehabilitation Engineering. 